\title{
Amperometric Detection of Superoxide Dismutase at Cytochrome $c$-Immobilized Electrodes: Xanthine Oxidase and Ascorbate Oxidase Incorporated Biopolymer Membrane for in-vivo Analysis
}

\author{
K. Vengatajalabathy GoBI ${ }^{\dagger}$ and Fumio MizuTANI
}

National Institute of Bioscience and Human-Technology, 1-1 Higashi, Tsukuba, Ibaraki 305-8566, Japan

\begin{abstract}
Amperometric measurement of superoxide dismutase (SOD) was carried out at cytochrome $c$-immobilized monolayers and ascorbate oxidase (AOD)/xanthine oxidase (XOD)/cytochrome $c$ - and (AOD, XOD)/cytochrome $c$-multilayers. Cytochrome $c$ was covalently immobilized on mercaptopropionic acid-containing self-assembled monolayers on gold. A biopolymer membrane of poly-L-lysine confining XOD and AOD was cast on the monolayer of cytochrome $c$. While both the cytochrome $c$-immobilized monolayer and multilayer electrodes show anodic current responses to the generation of superoxide radical, the sensitivity of the multilayer system for the detection of superoxide radical was high relative to that of the monolayer system. In the case of the cytochrome $c$-multilayer electrodes, the generation of superoxide radical near the sensing element, cytochrome $c$, resulted in high sensitivity for the detection of superoxide. The use of a XOD and AOD-incorporated poly-L-lysine membrane enabled the detection of the generation of superoxide radical in the presence of L-ascorbic acid. Though L-ascorbic acid could scavenge superoxide radical, the biopolymer membrane confined with AOD will oxidize any L-ascorbic acid that permeated into the membrane. By using the multilayer electrodes, one could measure the activity of SOD in the presence of L-ascorbic acid.
\end{abstract}

(Received September 18, 2000; Accepted October 2, 2000)

\section{Introduction}

Superoxide radical is highly reactive and short-lived and is formed in all aerobic cells. The superoxide radical generated during the "respiratory burst" of phagocytic cells plays an important role in the destruction of microorganisms invading into our body. But it may be involved in oxidative damage to tissues and organisms if it exceeds the level at which the systems are able to provide defence. The ubiquitous presence of SOD enzyme throughout the evolutionary chain emphasizes the importance of superoxide radical in cell function and survival. SOD plays a major protective role in living cells and has been widely used as a pharmacological tool in the study of pathophysiological mechanisms. ${ }^{1-6}$ Detection of superoxide and SOD has been intensively pursued by spectrophotometric and electrochemical methods..$^{7-16}$ Electrochemical sensors are of great interest due to their advantages, which include microfabrication and in-vivo and in-vitro applications. ${ }^{17,18}$ The hemoprotein, cytochrome $c$ (cyt $c$ ), undergoes facile reductive reaction with superoxide. Electrochemical biosensors for superoxide with cyt $c$ as the sensing element were constructed employing a suitable electron-transfer promoter. ${ }^{11-14}$ SOD is a selective scavenger of superoxide, and the best way for the detection of SOD thus could be the estimation of superoxide. Superoxide undergoes spontaneous disproportionation to produce $\mathrm{H}_{2} \mathrm{O}_{2}$, an electroactive species. Thus, the electrical response of the superoxide sensor system for interfering

$\doteqdot$ To whom correspondence should be addressed.

E-mail: kvgobi@nibh.go.jp compounds is a very important limitation in its application. We recently reported a selective detection of superoxide and SOD at cyt c/alkanethiol electrodes, where the response due to interferents was suppressed by the use of a mixed-monolayer of alkanethiols for anchoring cyt $c$; but the presence of L-ascorbic acid, a potential scavenger of superoxide existing ubiquitously in our body, was detrimental to the detection of superoxide and SOD. ${ }^{19}$ The detection of superoxide and consequently SOD in the presence of L-ascorbic acid was established using XOD/cyt $c$-bilayer electrodes, where the poly-L-lysine: polystyrenesulfonate complex membrane employed for the immobilization of XOD restricted the permeation of L-ascorbic acid across the membrane and consequently suppressed the scavenging of the superoxide produced at the membrane-bound XOD by Lascorbic acid. ${ }^{20}$ The XOD/cyt $c$-bilayer electrodes could detect SOD in the presence of L-ascorbic acid; however, the sensitivity of XOD/cyt $c$-bilayer electrodes for SOD was rather low (detection limit, $0.2 \mu \mathrm{g} \mathrm{ml}^{-1}$ ) relative to that of cyt $c$-monolayer electrodes (detection limit, $3 \mathrm{ng} \mathrm{ml}^{-1}$ ); ${ }^{19,20}$ the permeation of SOD across the polyion complex membrane confining XOD was suppressed in the case of the bilayer electrodes, which resulted into a low sensitivity for the detection of SOD. In the present investigation, the cyt $c$-immobilized monolayer electrodes were prepared by covalently-immobilizing cyt $c$ on mixed-monolayers of 3-mercaptopropionic acid (MPA) with the coadsorbate 3-mercaptopropanol (MP); a biopolymer membrane consisting of XOD and AOD was formed with poly-L-lysine on the monolayer of cyt $c$ to fabricate the cyt $c$-immobilized multilayer electrodes. The SOD sensor activity of the cyt $c$ immobilized monolayer and multilayer electrodes was pursued. We emphasize here, the features of the XOD and AOD- 
incorporated biopolymer membrane for enhanced sensor activity and in-vivo analysis. The fabricated cyt $c$-multilayer electrodes show rapid, large current response for the superoxide generated by xanthine-XOD enzymatic reaction. The SOD sensor activities of the cyt $c$-immobilized electrodes were pursued in the presence of L-ascorbic acid.

\section{Experimental}

\section{Reagents}

Cyt $c$ (from horse heart; ferric form), poly-L-lysine (MW 100000), SOD, AOD and catalase were purchased from Sigma and were used as supplied. 1-Ethyl-3-(3-dimethylaminopropyl)carbodiimide (EDC; Nacalai), XOD (Wako; $5 \mathrm{U} \mathrm{ml}^{-1}$ ), MPA (TCI), MP (TCI) and glutaraldehyde (glu; Aldrich) were used as received. Xanthine, L-ascorbic acid and supporting electrolytes were of analytical-reagent grade and were purchased from Kanto Chemical Co. Deionized water, purified by passage through a Millipore Milli-Q filtration system, was used to prepare all aqueous solutions.

\section{Fabrication of cyt c-immobilized monolayer electrodes}

Polycrystalline Au electrodes of $1.6 \mathrm{~mm}$ diameter (BAS) were polished with aqueous slurries of successively finer alumina powder (down to $0.06 \mu \mathrm{m}$ ) on polishing microcloth (BAS) and were sonicated in water. Electrodes were etched for $3 \mathrm{~min}$ in 1:3:6 (in volume) mixture of conc. $\mathrm{HNO}_{3} / \mathrm{conc}$. $\mathrm{HCl} /$ water and sonicated in water. Electrodes were then cleaned electrochemically in $0.05 \mathrm{M} \mathrm{H}_{2} \mathrm{SO}_{4}$ by potential cycling in the range of -0.2 to $1.5 \mathrm{~V}$ at the potential sweep rate of $10 \mathrm{~V} \mathrm{~s}^{-1}$ for $10 \mathrm{~min}$ or until the cyclic voltammogram (CV) characteristic of a clean Au electrode was obtained. The real surface area of the Au electrodes was determined by cyclic voltammetry from the charge required to reduce the surface oxide layer ${ }^{21}$ and was used in the calculations of surface coverage values. The surface roughness factor of the Au electrodes thus pretreated, calculated as the ratio of the real surface area to the geometric one, was 2.7 \pm 0.3 . The Au electrodes thus pretreated were dipped for $12 \mathrm{~h}$ in an ethanolic solution of $1.5 \mathrm{mM} \mathrm{MPA}+8.5 \mathrm{mM} \mathrm{MP}$, then rinsed sequentially with copious amounts of ethanol and water. They are denoted as Au/MPA + MP. The surface coverage $(\Gamma)$ of alkanethiols bound to Au electrodes was determined using the reductive desorption experiment, as described elsewhere, ${ }^{22,23}$ in $0.5 \mathrm{M} \mathrm{KOH}$ to be $(9.2-9.9) \times 10^{-10} \mathrm{~mol} \mathrm{~cm}{ }^{-2}$. This is equivalent to a monolayer coverage of alkanethiols on gold surface..$^{22-24}$ Cyt $c$ was covalently-immobilized on the MPA + MP mixed-monolayer electrode according to the reported procedure. ${ }^{19,20}$ For covalent immobilization of cyt $c$, Au/MPA + MP electrode was incubated at $25^{\circ} \mathrm{C}$ in aqueous $4 \mathrm{mM}$ sodium phosphate buffer (SPB; pH 7.0) containing $50 \mu \mathrm{M}$ cyt $c$ for 20 min, and the water-soluble condensing agent, EDC, was then added to give a final concentration of $2 \mathrm{mg} \mathrm{ml}^{-1} \mathrm{EDC}$. After 1 $\mathrm{h}$, the electrodes were rinsed with $4 \mathrm{mM} \mathrm{SPB}$ and the resulting electrode was defined as Au/cyt $c$. The amount of surfaceimmobilized cyt $c$ was determined from the cyclic voltammetric responses as charge in the cathodic wave $\left(Q_{\mathrm{p}}^{\mathrm{c}}\right)$ by the cut and weigh method.

\section{Fabrication of cyt c-immobilized multilayer electrodes}

On the cyt $c$-immobilized monolayer electrodes, a biopolymer membrane consisting of XOD and AOD was formed by adding a few microliters of each XOD $\left(5 \mathrm{U} \mathrm{ml}^{-1} ; 3.5 \mu \mathrm{l}\right)$, AOD $(2 \mathrm{U}$ $\left.\mu \mathrm{l}^{-1} ; 2 \mu \mathrm{l}\right)$, poly-L-lysine ( $25 \mathrm{mM}$ in monomer unit; $\left.2.5 \mu \mathrm{l}\right)$ and glutaraldehyde $(0.05 \% ; 2 \mu \mathrm{l})$ on top of the cyt $c$-immobilized

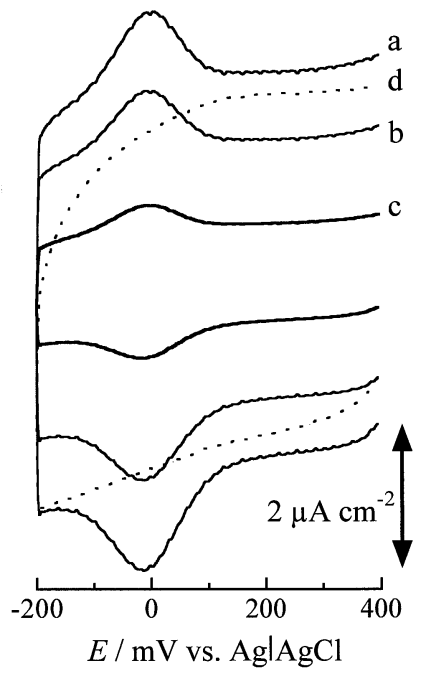

Fig. $1 \mathrm{CVs}$ of Au/cyt $c(\mathrm{a}-\mathrm{c})$ and Au/MPA + MP (d) recorded in aqueous $4 \mathrm{mM}$ SPB (pH 7.0). Potential sweep rates were 100 (a), 50 (b, d) and $20 \mathrm{mV} \mathrm{s}^{-1}$ (c). The MPA + MP Au-alkanethiolate layer was formed from an ethanol solution of 1.5 mM MPA + 8.5 mM MP.

monolayer electrodes and drying at $4^{\circ} \mathrm{C}$ for $2 \mathrm{~h}$, followed by drying at reduced pressure for $1 \mathrm{~h}$. The resulting electrode was denoted as Au/cyt c/PL:(XOD, AOD). Au/cyt c/PL:(XOD) electrode was prepared by excluding the addition of AOD in the above process. On Au/cyt c/PL:(XOD) electrode, AOD was then immobilized using poly-L-lysine as in the above process or using glutaraldehyde alone; the resulting electrodes were defined as Au/cyt c/PL:(XOD)/PL:(AOD) and Au/cyt c/PL:(XOD)/AOD glu, respectively. The amounts of XOD and AOD added in the biopolymer membrane were $17 \mathrm{mU}$ and $4 \mathrm{U}$, respectively. The fabricated bi- and tri-layer electrodes were dipped in $0.1 \mathrm{M}$ SPB ( $\mathrm{pH} 7.0$ ) for $30 \mathrm{~min}$ prior to the measurements.

\section{Measurements}

Electrochemical measurements were performed in a twocompartment three-electrode cell using a Cypress CS-1090 electrochemical measurement system. The working electrode and the counter electrode (a Pt spiral wire) were separated by a porous glass, and an $\mathrm{NaCl}$ saturated $\mathrm{Ag} \mid \mathrm{AgCl}$ electrode was used as the reference electrode. Stock solutions of SOD (10 U $\mu \mathrm{l}^{-1}$ in $\left.10 \mathrm{mM} \mathrm{SPB}\right)$ and xanthine $(15 \mathrm{mM}$ in $50 \mathrm{mM} \mathrm{NaOH})$ were prepared just before the measurements. Superoxide was generated by xanthine-XOD enzymatic reaction in oxygensaturated solutions (Eq. (1))..$^{25}$

$$
\mathrm{O}_{2} \text {, xanthine } \stackrel{\mathrm{XOD}}{\longrightarrow} \mathrm{O}_{2}^{-}, \mathrm{H}_{2} \mathrm{O}_{2} \text {, uric acid }
$$

Electrolyte solutions (SPB; $\mathrm{pH} 7.0$ ) were deaerated or oxygensaturated by bubbling argon or oxygen gas, respectively, for at least 30 min prior to electrochemical measurements; during the measurements, argon or oxygen gas was passed over the electrolyte solution.

\section{Results and Discussion}

Electrochemical characteristics of cyt $\mathrm{c}$ immobilized on Aualkanethiolate electrodes

Figure 1 shows the typical CVs of Au/cyt $c$ and Au/MPA + 


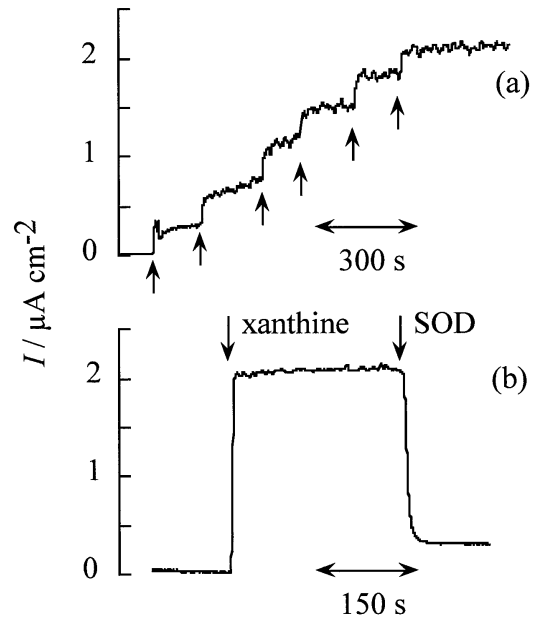

Fig. 2 Current-time curves of Au/cyt $c / \mathrm{PL}$ :(XOD) recorded at the applied potential of $0.15 \mathrm{~V}$ on successive additions of $0.15 \mathrm{mM}$ xanthine (a) and on the additions of $0.75 \mathrm{mM}$ xanthine and $300 \mathrm{U}$ $\mathrm{ml}^{-1} \mathrm{SOD}(\mathrm{b})$. Electrolyte solution was $0.1 \mathrm{M} \mathrm{SPB}$ (pH 7.0).

MP recorded in deaerated aqueous $4 \mathrm{mM}$ SPB at various potential sweep rates $\left(20-100 \mathrm{mV} \mathrm{s}^{-1}\right)$. The $\mathrm{CV}$ of $\mathrm{Au} / \mathrm{MPA}+$ MP shows only a double-layer charging current in the region of 400 to $-200 \mathrm{mV}$ (Fig. 1(d)). The cyt $c$-immobilized electrode shows a reversible redox wave with the formal potential, $E^{\circ}$ (taken as $\left.\left(E_{\mathrm{p}}^{\mathrm{c}}+E_{\mathrm{p}} \mathrm{a}\right) / 2\right)$, of $-0.01 \mathrm{~V}$. The redox response of $\mathrm{Au} / \mathrm{cyt} c$ is stable on consecutive potential cycling and is consistent with that anticipated for an electrochemically reversible reaction involving surface-immobilized species. For example, the peak currents vary linearly with the potential sweep rate $(v)$ in the range of 20 to $500 \mathrm{mV} \mathrm{s}^{-1}$, and the ratio of $I_{\mathrm{p}}{ }^{\mathrm{c}}$ to $I_{\mathrm{p}}{ }^{\mathrm{a}}$ at a given sweep rate is unity. The $E^{\mathrm{o}^{\prime}}$ of $\mathrm{Au} / \mathrm{cyt} c$, $-0.01 \mathrm{~V}$, is equal to those reported for cyt $c$ adsorbed or covalently-bound to the $\mathrm{COOH}$-terminated Au-alkanethiolate layers. ${ }^{26-28}$ The faradaic charge $Q_{\mathrm{p}}{ }^{\mathrm{c}}$ associated with the cathodic wave of cyt $c$ was $0.69 \mu \mathrm{C} \mathrm{cm}^{-2}$ (taking the real surface area of the Au electrode into account) independent of $v$ in the range of 20 to $500 \mathrm{mV} \mathrm{s}^{-1}$; the $\Gamma$ of cyt $c$ was determined to be $7.2 \times 10^{-12}$ mol cm$~^{-2}$. The determined $\Gamma$ value of cyt $c$ is a little higher than the theoretical monolayer surface coverage value of cyt $c, 6.8 \times$ $10^{-12} \mathrm{~mol} \mathrm{~cm}^{-2}$, calculated using the unit cell dimensions of cyt $c$ $(5.83,5.83$ and $4.18 \mathrm{~nm})$ and the area of a cyt $c$ molecule $(2400$ $\left.\AA^{2}\right) .{ }^{29,30}$ Thus, the fabricated Au/cyt $c$ electrode possesses a monolayer coverage of cyt $c$ covalently-immobilized on the Aualkanethiolate layer.

\section{Amperometric measurement of superoxide radical and SOD}

The activity of the cyt $c$-immobilized monolayer and multilayer electrodes for monitoring the superoxide generated by xanthine-XOD system was examined chronoamperometrically at $0.15 \mathrm{~V}$. The current-time curves of Au/cyt c/PL:(XOD) electrode recorded at an applied potential of $0.15 \mathrm{~V}$ for the superoxide generated on the additions of xanthine to the oxygen-saturated electrolyte solution of $0.1 \mathrm{M}$ SPB are shown in Fig. 2. The $\mathrm{O}_{2}^{-}$radical can undergo spontaneous dismutation into $\mathrm{O}_{2}$ and $\mathrm{H}_{2} \mathrm{O}_{2}$ in aqueous solution; the counterbalance between the generation of the $\mathrm{O}_{2}{ }^{-}$radical and its disproportionation will result in a constant equilibrium concentration of the $\mathrm{O}_{2}^{-}$radical. Before the addition, a stable back-ground current of $\sim 10 \mathrm{nA}$ $\mathrm{cm}^{-2}$ was recorded under the applied potential condition. Immediately after the addition of $0.15 \mathrm{mM}$ xanthine, the current was increased anodically and reached a plateau within $20 \mathrm{~s}$ (Fig.
Table 1 Current responses of the cyt $c$-immobilized electrodes for superoxide and SOD against the potential interferent and scavenger of superoxide, L-ascorbic acid, observed in $0.1 \mathrm{M} \mathrm{SPB}$ at the applied potential of $0.15 \mathrm{~V}$

\begin{tabular}{|c|c|c|c|}
\hline \multirow{2}{*}{ Electrode } & \multicolumn{3}{|c|}{ Current ${ }^{\mathrm{a}} / \mu \mathrm{A} \mathrm{cm}^{-2}$} \\
\hline & $\mathrm{O}_{2}{ }^{-\mathrm{b}}$ & $\mathrm{SOD}^{\mathrm{c}}$ & L-Ascorbic \\
\hline Bare Au & & & 10.0 \\
\hline $\mathrm{Au} / \mathrm{cyt} c^{\mathrm{e}}$ & $\begin{array}{l}0.15 \\
0^{f}\end{array}$ & 0.14 & $<0.1$ \\
\hline $\mathrm{Au} / \mathrm{cyt} c / \mathrm{PL}:(\mathrm{XOD})$ & $\begin{array}{l}2.10 \\
1.10^{\mathrm{f}}\end{array}$ & 0.18 & \\
\hline $\mathrm{Au} / \mathrm{cyt} c / \mathrm{PL}:(\mathrm{XOD}, \mathrm{AOD})$ & $\begin{array}{l}1.90 \\
1.90^{\mathrm{f}}\end{array}$ & $\begin{array}{l}0.18 \\
0.17^{f}\end{array}$ & $<0.1$ \\
\hline $\mathrm{Au} / \mathrm{cyt} c / \mathrm{PL}:(\mathrm{XOD}) / \mathrm{PL}:(\mathrm{AOD})$ & 1.40 & 0.07 & \\
\hline $\mathrm{Au} / \mathrm{cyt} c / \mathrm{PL}:(\mathrm{XOD}) / \mathrm{AOD}_{\text {glu }}$ & 1.50 & 0.07 & \\
\hline
\end{tabular}

a. The reported values were reproducible within the limits of $\pm 5 \%$. b. Anodic current observed for the addition of $0.75 \mathrm{mM}$ xanthine. c. Decrease in the anodic current for the addition of $3 \mathrm{U} \mathrm{ml}^{-1} \mathrm{SOD}$. d. Anodic current observed for the addition of $50 \mu \mathrm{M}$ L-ascorbic acid. e. Electrolyte solution contained $60 \mathrm{mU} \mathrm{ml}^{-1} \mathrm{XOD}$.

f. Current observed in the presence of $50 \mu \mathrm{M} \mathrm{L}$-ascorbic acid.

2(a)); on successive additions of xanthine, the current response increased stepwise anodically. The magnitude of the anodic current for the addition of $0.75 \mathrm{mM}$ xanthine recorded at $\mathrm{Au} / \mathrm{cyt}$ c/PL:(XOD) was $2.1 \mu \mathrm{A} \mathrm{cm}^{-2}$ (Fig. 2(b)). During the generation of superoxide radical, though the concentration of coproduced $\mathrm{H}_{2} \mathrm{O}_{2}$ and uric acid will increase with time (Eq. (1)), the observation of a steady-state current reveals that both $\mathrm{H}_{2} \mathrm{O}_{2}$ and uric acid interfere negligibly in the observed electrical response. The current-time curve of Au/cyt $c$ electrode recorded in an oxygen-saturated solution of $0.1 \mathrm{M} \mathrm{SPB}$ containing $60 \mathrm{mU} \mathrm{ml}^{-1}$ XOD showed an anodic current on the addition of $0.10 \mathrm{mM}$ xanthine and attained a plateau within $10 \mathrm{~s}$ (data not shown); the magnitude of the anodic current was $0.15 \mu \mathrm{A} \mathrm{cm} \mathrm{cm}^{-2}$ (Table 1). In contrary to $\mathrm{Au} / \mathrm{cyt} c / \mathrm{PL}:(\mathrm{XOD})$ electrode, the current response of $\mathrm{Au} / \mathrm{cyt} c$ did not increase anodically further on a successive addition of $0.15 \mathrm{mM}$ xanthine. The anodic current response recorded for the $\mathrm{O}_{2}{ }^{-}$radical generated by the enzymatic reaction at $\mathrm{Au} / \mathrm{cyt} c / \mathrm{PL}:(\mathrm{XOD})$ is very high relative to that recorded at $\mathrm{Au} / \mathrm{cyt} \quad c$. This observation clearly suggests that the immobilization of XOD in the vicinity of the sensing element, cyt $c$, enhanced the sensitivity for the detection of $\mathrm{O}_{2}^{-}$radical. Moreover, it further reveals that the $\mathrm{O}_{2}{ }^{-}$radical generated near the electrode surface only would undergo electrochemical oxidation reaction at the electrode surface, leaving the $\mathrm{O}_{2}$ radical generated far from the electrode surface and in bulk electrolyte solution to undergo mainly a disproportionation process. In a control experiment, Au/cyt $c / \mathrm{PL}$ :(XOD) electrode fabricated without the presence of XOD in the biopolymer membrane gave no current response for the addition of xanthine. Moreover, the addition of SOD, a selective scavenger of $\mathrm{O}_{2}{ }^{-}$radical, caused the anodic current to decrease by $>85 \%$ within $20 \mathrm{~s}$ (Fig. 2(b)). All the observations clearly demonstrate that only the $\mathrm{O}_{2}^{-}$radical generated by the xanthine-XOD system was giving the anodic current response. Here, the residual anodic current observed in the presence of SOD (Fig. 2(b)) would be due to the electrocatalytic oxidation of the $\mathrm{O}_{2}{ }^{-}$radical that had not been accessed by SOD, because of the generation of $\mathrm{O}_{2}{ }^{-}$radical in the proximity of the surface-immobilized cyt $c$.

The cyt $c$-immobilized electrodes were examined for the detection of $\mathrm{O}_{2}^{-}$radical in the presence of $\mathrm{L}$-ascorbic acid. $\mathrm{L}$ - 


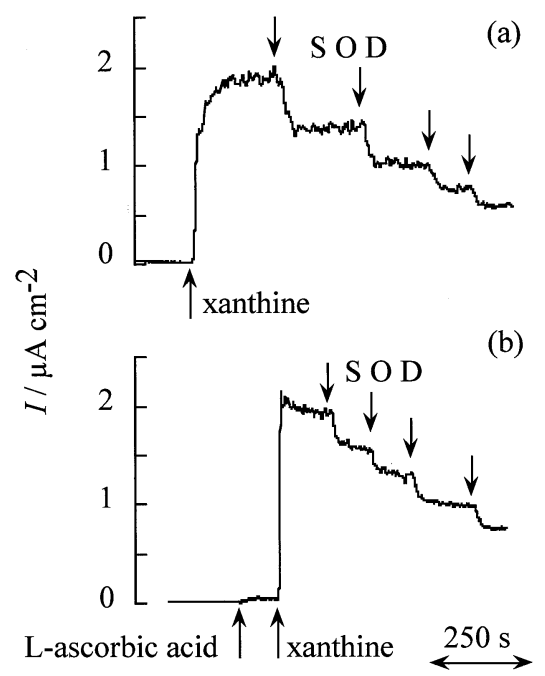

Fig. 3 (a) Current-time curves of Au/cyt $c / \mathrm{PL}$ :(XOD, AOD) on the additions of $0.75 \mathrm{mM}$ xanthine and $15,30,45$ and $60 \mathrm{U} \mathrm{ml}^{-1} \mathrm{SOD}$; (b) current-time curves of Au/cyt $c / \mathrm{PL}$ :(XOD, AOD) on the additions of $50 \mu \mathrm{M}$ L-ascorbic acid, $0.75 \mathrm{mM}$ xanthine and $15,30,45$ and $60 \mathrm{U}$ $\mathrm{ml}^{-1}$ SOD. Other conditions are the same as in Fig. 2 .

Ascorbic acid is available in blood at concentrations of $\sim 50$ $\mu \mathrm{M} .{ }^{31,32}$ Figure 3 shows the current-time curves of Au/cyt $c / \mathrm{PL}$ :(XOD, AOD) observed at $0.15 \mathrm{~V}$ for the $\mathrm{O}_{2}^{-}$radical generated on the addition of xanthine in the presence and absence of $50 \mu \mathrm{M} \mathrm{L-ascorbic} \mathrm{acid.} \mathrm{In} \mathrm{the} \mathrm{presence} \mathrm{of} \mathrm{L-}$ ascorbic acid, $\mathrm{O}_{2}^{-}$radical will be quenched by a reductive reaction (Eq. (2)) and thus the amperometric response of the $\mathrm{O}_{2}$ radical would diminish.

L-ascorbic acid $+2 \mathrm{O}_{2}^{-}+2 \mathrm{H}^{+}$ $\longrightarrow$ dehydroascorbic acid $+2 \mathrm{H}_{2} \mathrm{O}_{2}$

The steady-state back-ground current of Au/cyt c/PL:(XOD, AOD) was $\sim 10 \mathrm{nA} \mathrm{cm}{ }^{-2}$. The addition of $50 \mu \mathrm{M} \mathrm{L}$-ascorbic acid gave a very small anodic current response, $<0.05 \mu \mathrm{A} \mathrm{cm} \mathrm{cm}^{-2}$ (Fig. 3(b)). The observed anodic current could be associated with the electrooxidation of L-ascorbic acid. At a bare $\mathrm{Au}$ electrode, $50 \mu \mathrm{M}$ L-ascorbic acid gave an anodic current of 10 $\mu \mathrm{A} \mathrm{cm}^{-2}$ at $0.15 \mathrm{~V}$ in $0.1 \mathrm{M}$ SPB (Table 1 ). The anodic currents observed for L-ascorbic acid at the cyt $c$-immobilized multilayer electrodes were enormously lower than that observed at a bare $\mathrm{Au}$ electrode. On the addition of xanthine, while no anodic current response was observed at Au/cyt $c$ in the presence of Lascorbic acid (Table 1), an anodic current of $1.9 \mu \mathrm{A} \mathrm{cm}^{-2}$ was recorded at Au/cyt $c / \mathrm{PL}$ :(XOD, AOD) (Fig. 3) irrespective to the presence or absence of L-ascorbic acid. At Au/cyt $c / \mathrm{PL}:(\mathrm{XOD}, \mathrm{AOD})$, the ascorbate oxidase enzyme existing in the biopolymer membrane oxidized the L-ascorbic acid molecules that permeated into the membrane and thus the scavenging of superoxide radical by L-ascorbic acid has been resisted. As one example of the above discussion, the cyt $c$ multilayer electrode fabricated without the presence of AOD in the poly-L-lysine membrane, Au/cyt c/PL:(XOD), showed an anodic current of $1.1 \mu \mathrm{A} \mathrm{cm}-2$ (Table 1) for the addition of xanthine in the presence of $50 \mu \mathrm{M}$ L-ascorbic acid, which is considerably lower than that recorded, $2.1 \mu \mathrm{A} \mathrm{cm} \mathrm{cm}^{-2}$, in the absence of L-ascorbic acid (Fig. 2(b)). The anodic currents recorded for the generation of superoxide radical at Au/cyt c/PL:(XOD)/PL:(AOD) and Au/cyt c/PL:(XOD)/AOD glu are lower than that recorded at Au/cyt $c / \mathrm{PL}$ :(XOD, AOD) (Table 1).

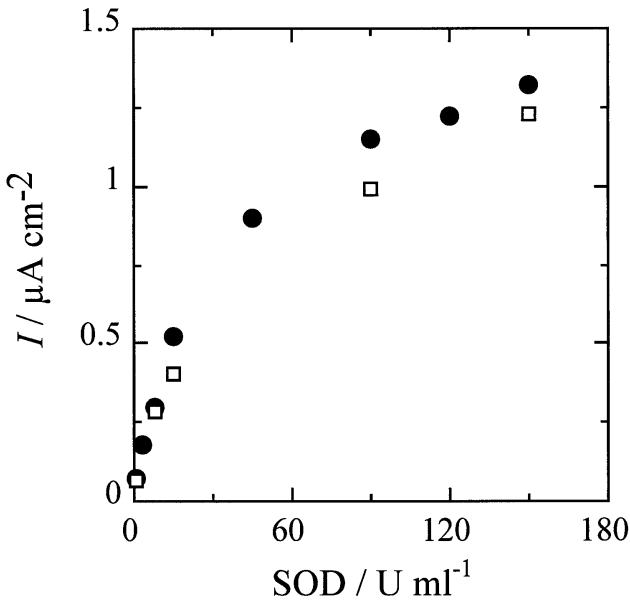

Fig. 4 Decrease in the anodic current response for the superoxide radical generated by XOD-xanthine enzymatic reaction observed at Au/cyt c/PL:(XOD, AOD) was plotted against the amount of SOD enzyme added. Electrolyte solutions were 0.1 M SPB (pH 7.0) (solid circles) and $+50 \mu \mathrm{M}$ L-ascorbic acid (rectangles), and the applied potential was $0.15 \mathrm{~V}$.

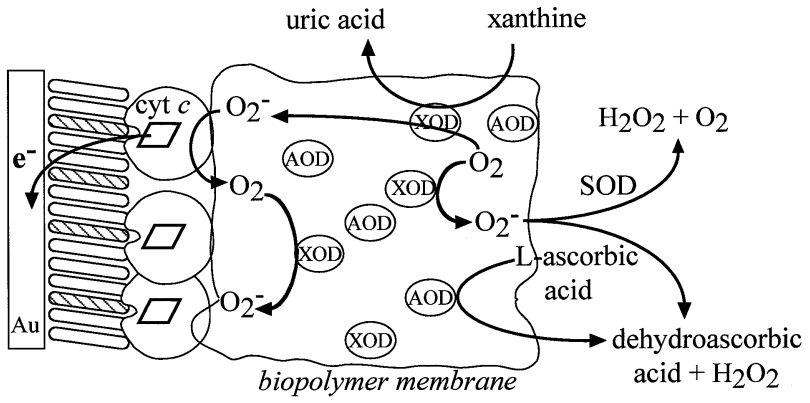

\section{$\square$ - heme redox center of cyt $c$}

Fig. 5 Schematic illustration of the reactions which took place at the SOD sensing cyt $c$-immobilized multilayer electrodes Ferricytochrome $c$, SOD and L-ascorbic acid react competitively with the superoxide generated in the biopolymer membrane of the multilayer electrode.

Among the cyt $c$-immobilized electrodes examined (Table 1), $\mathrm{Au} / \mathrm{cyt} c / \mathrm{PL}:(\mathrm{XOD}, \mathrm{AOD})$ is preferable for the detection of superoxide in the presence of L-ascorbic acid.

The current responses of Au/cyt $c / \mathrm{PL}$ :(XOD, AOD) for the addition of different amounts of SOD were recorded (Fig. 3) both in the presence and absence of L-ascorbic acid. The anodic current response of the $\mathrm{O}_{2}^{-}$radical decreases on the addition of SOD. Immediately after the addition of SOD, the steady-state anodic current of the $\mathrm{O}_{2}{ }^{-}$radical decreases and attains a steadystate within $20 \mathrm{~s}$. The amount of decrease in the anodic current was plotted against the amount of SOD added (Fig. 4). The magnitude of the current response for the addition of SOD did not differ considerably by the presence of L-ascorbic acid (50 $\mu \mathrm{M})$ in the electrolyte solution. At Au/cyt $c / \mathrm{PL}:(\mathrm{XOD}, \mathrm{AOD})$, thus, the SOD enzyme could be detected amperometrically, irrespective of the presence of as much as $50 \mu \mathrm{M}$ of L-ascorbic acid. The different reactions took place at the cyt $c$-multilayer electrodes are given in Fig. 5. The $\mathrm{O}_{2}^{-}$radical generated in the biopolymer membrane would be electrocatalytically oxidized by 
the immobilized cyt $c$ to give an anodic current response. Superoxide radical diffusing out of the biopolymer membrane undergoes disproportionation, SOD-assisted dismutation and quenching with L-ascorbic acid and thus could not contribute in the amperometric response. The quenching of superoxide radical by L-ascorbic acid and SOD permeated into the membrane produces a current response. In the detection of $\mathrm{SOD}$, the $\mathrm{O}_{2}^{-}$radical generated by the XOD-xanthine enzymatic reaction in the biopolymer membrane will undergo a competitive reaction with cyt $c$, L-ascorbic acid and SOD $\mathrm{Au} / \mathrm{cyt} c / \mathrm{PL}:(\mathrm{XOD}, \mathrm{AOD})$ responds to the addition of SOD in the concentration range of 0.5 to $300 \mathrm{U} \mathrm{ml}^{-1}$ and thus could be used for the detection of SOD as low as $0.5 \mathrm{U} \mathrm{ml}^{-1}\left(\sim 50 \mathrm{ng} \mathrm{ml}^{-1}\right.$, signal-to-noise ratio $=3$ ) in the presence of as much as $50 \mu \mathrm{M}$ of L-ascorbic acid.

\section{Acknowledgements}

K. V. G. gratefully acknowledges the Japan Science and Technology (JST) for financial support.

\section{References}

1. M. Tarr and F. Samson, "Oxygen Free Radicals in Tissue Damage", 1993, Birkhauser, Boston.

2. J. T. Hancock, Br. J. Biomed. Sci., 1997, 54, 38.

3. J. A. Badwey, J. T. Curnette, and M. L. Karnovsky, N. Eng. J. Med., 1979, 300, 1157.

4. A. M. Michelson, J. M. McCord, and I. Fridovich, "Superoxide and Superoxide Dismutases", 1977, Academic Press, London.

5. D. K. Das and N. Maulik, Methods Enzymol., 1994, 233 , 601.

6. B. Halliwell and J. M. C. Gutteridge, Biochem. J., 1984 $219,1$.

7. J. M. McCord and I. Fridovich, J. Biol. Chem., 1969, 244, 6049.

8. I. Fridovich, Adv. Enzymol., 1986, 58, 61.

9. B. M. Babior, R. S. Kipnes, and J. T. Curnette, J. Clin. Invest., 1973, 52, 742

10. K. Tanaka, F. Kobayashi, Y. Isogai, and T. Iizuka, Bioelectrochem. Bioenerg., 1991, 26, 413.

11. P. Manning, C. J. McNeil, J. M. Cooper, and E. W
Hillhouse, Free Rad. Biol. Med., 1998, 24, 1304.

12. J. M. Cooper, K. R. Greenough, and C. J. McNeil, J. Electroanal. Chem., 1993, 347, 267.

13. F. Lisdat, B. Ge, E. E. Forster, and F. W. Scheller, Anal. Chem., 1999, 71, 1359.

14. W. Scheller, W. Jin, E. E. Forster, B. Ge, F. Lisdat, R. Buttemeier, U. Wollenberger, and F. W. Scheller Electroanal., 1999, 11, 703.

15. S. Goldstein, C. Michel, W. Bors, M. Saran, and G. Czapski, Free Rad. Biol. Med., 1988, 4, 295.

16. H. Ukeda, A. K. Sarker, D. Kawana, and M. Sawamura, Anal. Sci., 1999, 15, 353.

17. F. Mizutani and M. Asai, in "Bioinstrumentations", ed. D. L. Wise, 1990, Butterworths, Boston, 317.

18. A. Heller, Acc. Chem. Res., 1990, 23, 128.

19. K. V. Gobi and F. Mizutani, J. Electroanal. Chem., 2000 $484,172$.

20. K. V. Gobi, Y. Sato, and F. Mizutani, Electroanal., in press.

21. E. Gileadi, E. K. Eisner, and J. Penciner, "Interfacial Electrochemistry", 1975, Addison-Wesley, Massachusetts, 437.

22. C. A. Widrig, C. Chung, and M. D. Porter, J. Electroanal. Chem., 1991, 310, 335.

23. K. V. Gobi, T. Okajima, K. Tokuda, and T. Ohsaka, Langmuir, 1998, 14, 1108.

24. S. Imabayashi, M. Iida, D. Hobara, Z. Q. Feng, K. Niki, and T. Kakiuchi, J. Electroanal. Chem., 1997, 428, 33.

25. J. S. Olson, D. P. Ballou, G. Palmer, and V. Massey, J. Biol. Chem., 1974, 249, 4350

26. M. J. Tarlov and E. F. Bowden, J. Am. Chem. Soc., 1991 $113,1847$.

27. T. Ruzgas, L. Wong, A. K. Gaigalas, and V. L. Vilker, Langmuir, 1998, 14, 7298.

28. S. Arnold, Z. Q. Feng, T. Kakiuchi, W. Knoll, and K. Niki, J. Electroanal. Chem., 1997, 438, 91.

29. G. W. Bushnell, G. V. Louie, and G. D. Brayer, J. Mol. Biol., 1990, 214, 585.

30. R. E. Dickerson, T. Takano, D. Eisenberg, O. B. Kallai, L. Samson, A. Cooper, and E. Margoliash, J. Biol. Chem., 1971, 246, 1511.

31. M. Nishikimi, Biochem. Biophys. Res. Comms., 1975, 63, 463.

32. R. Maidan and A. Heller, Anal. Chem., 1992, 64, 2889. 